\title{
Enhancing Cognitive Development in Learning Chemical Symbol and Periodicity through Instructional Game
}

\author{
Hassan Aliyu ${ }^{*}$ * Chttps://orcid.org/0000-0003-4929-3126, Yasheni Raman ${ }^{2}$, Corrienna Abdul Talib ${ }^{3}$ \\ (Dhttps://orcid.org/0000-0003-2230-3670 \\ ${ }^{1}$ Sokoto State University, Nigeria, ${ }^{2,3}$ Universiti Teknologi Malaysia, Malaysia \\ *e-mail: aliyu.hassan@ssu.edu.ng
}

\section{Article Information}

Received: December 12, 2020

Revised: March 15, 2021

Accepted: May 05, 2021

Online: August 09, 2021

\section{Keywords}

The instructional game, Cognitive development, Chemistry

\begin{abstract}
A digital instructional game with embedded multimedia was believed not limited to allowing the learner to visualize chemistry concepts while playing but enable them to collect relevant information that connects the understanding of the other. The subject was described as a core science area with multiple macroscopic, submicroscopic, and symbolic representations. Thus, the study intended to investigate the effectiveness of the instructional game in enhancing students' cognitive development in learning chemical symbols and periodicity of elements. An instructional tool called "Symperiod Board Game) The study was designed and developed, containing 20 test items distributed in three different levels in order of complexity from simple to complex. The between-group experimental research design was adopted for this study in which 20 Form IV students distributed into four groups were selected. The alpha value 0.830 of the Pearson correlation coefficient determines the strength of the instrument's reliability, hence used for data collection. The data obtained were analyzed using descriptive statistics, and the results indicated that the cognitive development of the respondents increases as students play the instructional game from level 1 to 3. Thus, the study reveals that a learner cannot understand a concept if he/she does not first remember it; similarly, he/she cannot apply knowledge and concepts if he/she does not understand them. It is imperative to conclude that the poor performance of students in chemistry can be associated with the quality of instruction provided by the teacher during classroom instructions.
\end{abstract}

\section{INTRODUCTION}

Generally, chemistry occupies the core area of science and is the most crucial field of study that empowers its learners and society through entrepreneurial skills. It formed a shred of solid evidence that made scholars consider it a vital science subject (Edomwonyi-otu \& Avaa, 2011). A study conducted by Martina Eya (2016) to investigate the chemistry contents that can best promote the acquisition of entrepreneurial skills and the approaches for teaching them among our students reveals that over 33 concepts in the secondary school chemistry curriculum promote the inculcation of entrepreneurial skills. Thus, chemistry classroom instructions should be result-oriented and students centred (Edomwonyi-otu \& Avaa, 2011). Therefore, teachers need to guide their students to become active and independent learners, thereby taking responsibility for their progress rather than relying on an 
instructor to tell them what is right or wrong (Smith, 2011). Many scholars (Bugaje, 2013; Chiu \& Wu, 2009; Edomwonyi-otu \& Avaa, 2011; Sanchez, 2017 and Stieff \& Wilensky, 2003) reported that a significant number of secondary schools' students believed that chemistry is a complex science subject due to its abstract nature, mathematics nature, terminological nature, symbolic nature, and modeling and syllable complexity. It made chemistry teachers teach chemistry concepts to their stud ents based on what they know, but how they know it, and what they think about the way they know it. In this vein, professional and experienced teachers are challenged to utilize varying instructional strategies to provide an excellent educational experience to their students (Aliyu et al., 2020). It became necessary that chemistry teachers create additional activities that may engage learners' understanding more deeply into developing cognitive skills through instructions, either in the classroom or somewhere else.

Consequently, one of the most challenging factors in creating an excellent instructional experience for the students is developing and maintaining learners' interest and motivation in learning. Will the instructional activity introduced by the chemistry teachers motivate students toward learning? How can we teach chemistry to students to move away from the perception that chemistry is inherently tricky? (Smith, 2011). To develop and maintain students' interest and motivation in learning chemistry, teachers need to provide classroom activities to foster active and independent student engagement. Today's students need a conceptual approach to scientific knowledge (Smith, 2011).

A study conducted by Edomwonyi-otu \& Avaa (2011) to investigate the causes of students' poor performances in chemistry at the secondary level of education in Nigeria reported that many respondents were with a view that they would have performed better if exposed to activities in the classroom that are interesting and appealing to adequate cognition. Because chemistry teachers display mathematical formulas, chemical names \& symbols, and scientific measurements simultaneously to describe phenomena that are not readily apparent to students (Stieff \& Wilensky, 2003) thus, chemistry teachers should not be reluctant to change that may lead to profound improvements in educational outcomes, thereby enhancing student performance and depth of learning. Students are described as curious by their nature; they need to be actively involved in the learning process in which they are continuously equipping, testing, speculating, and building their construct and knowledge. The human brain is not a passive consumer of information, and to learn with understanding, a learner must actively construct the meaning of what is to be learned. Thus, this necessitates considering multiple representations or levels of representation as reported by (Talanquer 2011).

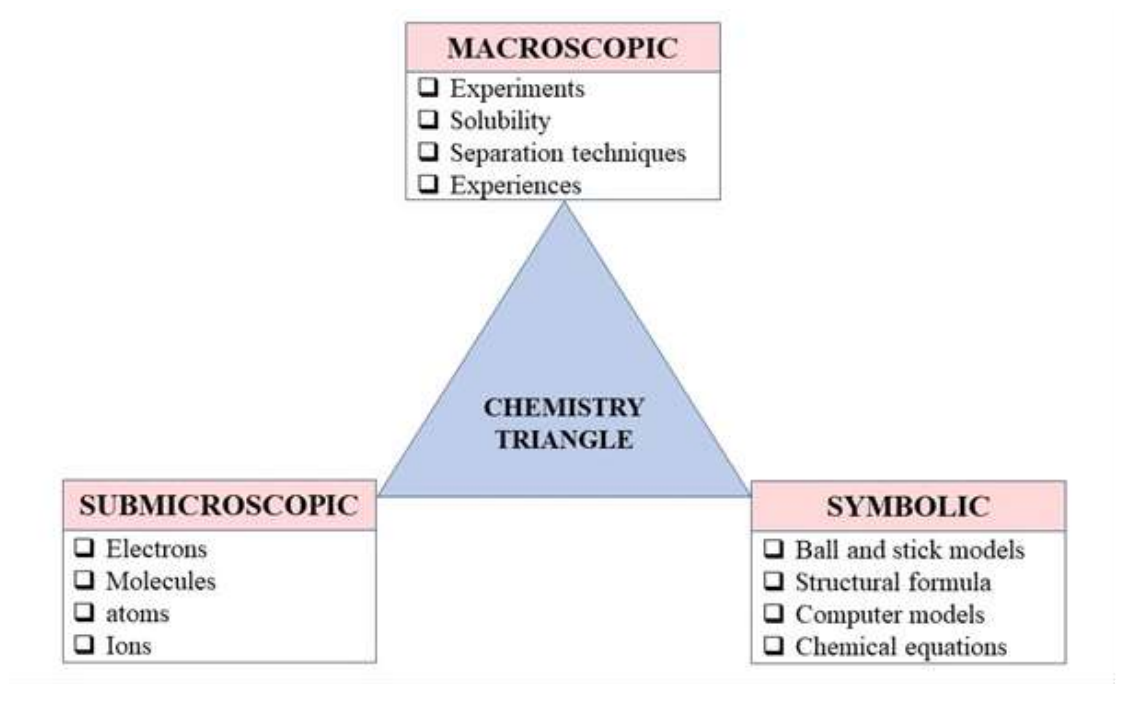

Figure 1. Chemistry Triangle Model (Johnstone, 1982)

These representations, namely, macroscopic, submicroscopic, and symbolic modes, constitute a fundamental model in chemistry (Gilbert \& Treagust, 2009). This model reduces memory overload and clarifies confusion of descriptive language (Bradley, 2014). Moreover, the significance of the model lies in the use of different modes in each level of representation. These modes vital in learning acquisitions 
include practical work, gestures, structural and virtual representations, photographs, symbols, diagrams, graphs, and chemical and mathematical equations.

Initially, Chiu \& Wu (2009) conducted a study to find out how multimedia could enhance chemistry learning of the triplet relationship. In the study, authors view multimedia as a modeling tool, learning tool, assessment tool, and instructional tool. The study reveals that multimedia allows the students to visualize chemical concepts and collect relevant information that could connect one concept to understanding others. Sanchez (2017) conducted a study titled "integrated macro-micro-symbolic approach in teaching secondary chemistry" to investigate the effectiveness of the Integrated MacroMicro-Symbolic Approach (IMMSA) in teaching chemistry to 10th graders of a secondary school in Cebu City, Philippines. The investigation proceeded with a pre-and-post-test (quasi-experimental design). Interestingly, the study's finding revealed the practical nature of integrating macroscopic, microscopic, and symbolic modes in teaching Chemistry concepts by enhancing students' performance.

Johnstone (1982) mentioned that an overload could occur at the early stages of learning chemistry because of the very nature of the subject (multiple - levels learning). The chemistry curriculum was designed spirally, from simple to complex, and learning some areas/concepts are a prerequisite for understanding others. For example, as chemistry occupies the central position in learning science (Biology and Physics), concepts like atoms, elements, molecules, and the periodic table are a core aspect of the subject that facilitate learning of other areas (organic, electrolysis, electrochemistry, rate of chemical reaction, solubility, acids, base, alkaline and more). The bases of understanding atoms, elements, molecules, and period tables are chemical symbols and periodicity of substances, hence become an area of emphasis of this study. Students' poor cognitive development is associated with a lack of interest in learning chemistry and motivation to persist in mastering complex chemistry concepts, and inadequate instructional approaches to chemistry education (Plass et al., 2014). Thus, the instructional game would be the appropriate approach for this study.

\section{Instructional Games in Learning Chemistry}

The role of a secondary school chemistry teacher is to utilize appropriate learning approaches, such as inquiry-based learning, cooperative learning (Bugaje, 2013), problem-solving, and even use concept mapping or instructional games for classroom instruction that could enhance innovative learning, cognitive development, and positive attitude toward learning. However, one must understand that a good knowledge of chemistry (subject matter), understanding of basic principles of child development about their learning, and the ability to employ varying instructional strategies on different concepts effectively. Furthermore, the ability to adopt good classroom instruction under the local situation, especially when students needed your creativity in learning complex concepts and prerequisites for understanding other areas in the subject, were some of the primary teacher's qualities that guarantee effective learning. The instructional game, whether designed for education or training, directly focuses on active learner participation. Hays (2005) defines games as "an artificially constructed, competitive activity with a specific goal, a set of rules and constraints located in a specific context." For an instructional game to be used in teaching, one needs to evaluate if the activities in the game itself can lead to the attainment of the stated goals of the instruction. While developing games, objectives and the learner's needs are crucially identified as the first step in the process. Instructional goals served a purpose in the learning process, and that they may lead to greater cognition, skill-based, and attitudinal gains over traditional instructional methods (Wilson et al., 2009).

Wilson et al. (2009) indicated that instructional games positively influence students in cognitive development, skill enhancement, and good attitudes toward learning. They maintained that instructional game is characterized by many attributes, including adaptation, assessment, challenge, conflict, control, fantasy, interaction (equipment), interaction (interpersonal), interaction (social), language/communication, location, mystery, pieces, or players, progress and surprise, representation, rules/goals (also referred to as game aims or objectives), safety, and sensory stimuli. While fun and entertainment were generally the first things that attract people to games, practical principles or approaches were embedded during the designs of instructional games to provide an engaging learning experience and facilitate positive learning outcomes ( $\mathrm{Li} \& \mathrm{Tsai}, 2013$ ). Pedagogical principles alone cannot constitute an exciting and attractive game that motivates students to play, hence the need for a 
digital game characterized by goals, rules, interactivity, feedback, and challenges. It was unanimously agreed by the scholars (Gee, 2007 and Li \& Tsai, 2013) that well-designed digital instructional games could motivate and promote effective learning by providing opportunities for learners to actively and critically experience, practice, and reflect on their ideas in a problem-based, situated, and low-risk context. Many scholars (Divjak \& Tomic, 2011; Egenfeldt-Nielsen, 2006; Mayer \& Johnson, 2010 and Vogel et al., 2006) showed better results in cognitive development, problem-solving skills, motivation, and attitudes toward learning. Specifically, Li \& Tsai (2013) emphasized that most of the digital instructional games were utilized to promote scientific knowledge/concept learning, cognitive development, and facilitation of the development of students' problem-solving skills. Thus, the ability of digital instructional games to raise students' motivation and facilitate their learning engagingly and joyfully draws the attention of this study's research.

\section{Theoretical Framework}

The cognitive theory of multimedia learning is appropriate for this study based on the result of the study conducted by (Li \& Tsai, 2013) to review empirical research articles regarding game-based learning published from 2000 to 2011, indicating that cognitivism and constructivism were the major theoretical foundations employed by the game-based learning researchers. The Cognitive Theory of Multimedia Learning (CTML) is based on the three cognitive science principles of learning; the human information processing system includes dual channels of visual/pictorial auditory/verbal processing (i.e., dual-channel assumption). Each channel has a limited capacity for processing (i.e., limited capacity assumption), and active learning entails carrying out a coordinated set of cognitive processes during learning (i.e., active processing assumption) (Mayer, 2005). The theory specifies five cognitive processes in multimedia learning: selecting relevant words from presented text or narration, selecting a relevant image from the presented illustrations, organizing the selected words into a coherent verbal representation, organizing the selected image into a coherent pictorial representation, and integrate the pictorial and representations and prior.

Table 1. Five Cognitive Processes in the Cognitive Theory of Multimedia Learning

\begin{tabular}{cll}
\hline S/N & \multicolumn{1}{c}{ Process } & \multicolumn{1}{c}{ Description } \\
\hline 1 & Selecting Words & $\begin{array}{l}\text { Learning pays attention to relevant words in a multimedia message } \\
\text { to create sounds in working memory. } \\
\text { Learner pays attention to relevant pictures in a multimedia } \\
\text { message creates images in working memory. } \\
\text { The learner builds connections among selected words to create a } \\
\text { coherent verbal model in working memory. } \\
\text { The learner builds connections among selected images to create a } \\
\text { coherent pictorial model in working memory. } \\
\text { The learner builds connections between verbal and pictorial } \\
\text { models and with prior knowledge. }\end{array}$ \\
& Organizing words & Organizing Images \\
\hline
\end{tabular}

To determine which theories of learning are most relevant to investigating the impacts of the game attribute (Wilson et al., 2009), consider Kraiger et al., (1993) theory because the theory is based on cognitive, social, and human factors research. For the game, the theoretically based model of learning outcomes is a multidimensional, construct-oriented approach to learning-cognitive, skill-based, and practical outcome. An activity is intrinsically motivated if people engage in it "for its own sake" if they do not engage in the activity to receive some external reward such as money or status. The reward here should not be conceived as reinforcement. For every interactive digital or non-digital instructional game, positive reinforcement motivates the player to continue playing, and negative reinforcement encourages the player to improve their performance next time.

\section{The objective of the study}


The study intended to investigate the effectiveness of the instructional game in enhancing students' cognitive development in learning chemical symbols and the periodicity of elements. This study will identify specific problems in teaching and learning chemistry, use relevant theories and theories of learning, use various attributes of the instructional game to overcome the difficulty, and finally design and develop an instructional game that may facilitate the achievement of stated instructional objectives. The study designed and developed an instructional game using Ullman (1997) Process model. It is an engineering project model used to develop objects/tools/instruments, including those that can fit into the teaching and learning process. The developmental stages as identified by Ullman (1997) process model are:

Table 2. Ullman (1997) Process Model

\begin{tabular}{|c|c|c|}
\hline Stages & & Activities Adopted for the Study \\
\hline Stage 1 & Needs identification & $\begin{array}{l}\text { Learners need cognitive development in learning } \\
\text { chemical symbols and periodicity }\end{array}$ \\
\hline Stage 2 & Planning for the design process & $\begin{array}{l}\text { Through Function Analysis, all components that lead } \\
\text { to the practical design of the product could cater to the } \\
\text { learners' needs. These components include a digital } \\
\text { board game, activities slides }\end{array}$ \\
\hline Stage 3 & $\begin{array}{l}\text { Development of engineering } \\
\text { specifications }\end{array}$ & $\begin{array}{l}\text { Materials for the board game and activities slides } \\
\text { include a piece of glass, quartz, frame, battery, LED } \\
\text { bulb, sound device, light sensors, copper wire, iron } \\
\text { plate, gum, cello tape, and colored beads. }\end{array}$ \\
\hline Stage 4 & Development of the concept & $\begin{array}{l}\text { In this stage, the engineering design process, the } \\
\text { objective of the study, cognitive theory of multimedia } \\
\text { learning, chemistry content area was aligned to make } \\
\text { sure that the instrument does what it was meant to do. } \\
\text { An interactive board game provides instant feedback } \\
\text { to the students (players), thereby developing an urge } \\
\text { to play again and again. }\end{array}$ \\
\hline Stage 5 & Development of the product & $\begin{array}{l}\text { A board game (Symperiod Board Game) containing } \\
\text { light and sound as re-enforcement to the challenge is } \\
\text { indicated in Figure } 1 \text {. It has a port through which } \\
\text { question and answer plates can be slide-in by the } \\
\text { students. Test items of different spiral levels of } \\
\text { complexity are developed to engage users in various } \\
\text { activities. }\end{array}$ \\
\hline
\end{tabular}

In order to ensure that the product meets the learners' needs, the instruction, and the stated

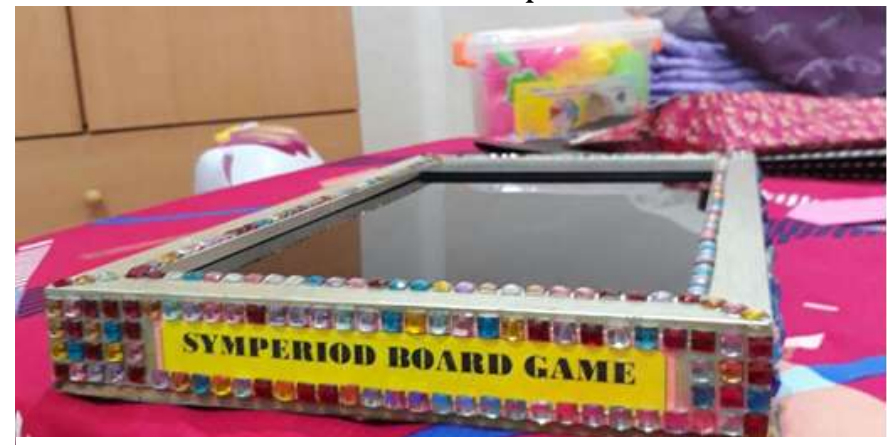

Figure 2. Symperiod Board Game (SBG), a tool for enhancing students' cognitive development instructional goals, each step was systematically followed with continuous evaluation by the expert. The project is set to develop the cognitive skills of the player.

\section{METHODS}

In order to adopt an appropriate approach for the data collection in this study, the nature of this research has to be carefully studied. By conceptualizing the type of research design, a study is confined to will enable the researcher to identify and manipulate his research 
variables accordingly and systematically. The between-group experimental research design was adopted for this study in which the data will be collected through actual experimental design.

The instructional game developed to consist of different activities of the chemical symbol of the elements, which were categorized in levels based on complexity. The levels are structured in a way that will enhance the cognitive development of learners. For this study, form IV students who have already learned the chemical symbol concept and periodicity were chosen. These students are beginners of chemistry and could face difficulties in learning chemical symbols and periodicity. There are 20 students in each classroom; thus, the respondents were divided into four groups comprising five members.

A test was developed containing 20 multiple-choice questions. Each item has three alternative options in which one is correct. Students from each group were given 30 minutes to answer the questions. Alphabets are assigned to groups to differentiate each group, Group A, Group B, Group C, \& Group D. The table below shows the grouping distribution in the experimentation.

Table 3. Procedure for the Experiment

\begin{tabular}{cllll}
\hline Groups & & 1st Test & \multicolumn{1}{c}{ Treatment } & 2nd Test \\
\hline A & Control group & Pre-test & No treatment & Post-test \\
B & Experimental group & Pre-test & Treatment Level 1 & Post-test \\
C & Experimental group & Pre-test & Treatment Level 1\&2 & Post-test \\
D & Experimental group & Pre-test & Treatment Level 1,2\&3 & Post-test \\
\hline
\end{tabular}

It can be seen clearly from the above table that Group A is the control group while Group B, C, and $\mathrm{D}$ are the experimental groups. For the experimental group only, a pre-test was administered, and no post-test. Remember that we stated earlier that the 'Symperiod Board Game (SBG)' was composed of different levels of complexity designed to burst learners' cognitive skills. These levels were distributed to the respective experimental groups to determine the effectiveness of the project.

Group B students are given five minutes to play the game with only level 1 activities and later administered the test to determine the group level of cognition. Group C students are given 10 minutes to complete level $1 \& 2$ activities and later administered the test. At the same time, Group D was given 15 minutes to play the game with level 1,2 , \& 3 activities and later administered the test. The researchers hoped that the sample for this study would be excited to study the chemical symbol of the elements and their periodicity and seek more understanding of the other concepts in chemistry.

The authors classified students' performances while using cognitive tools to enhance cognitive development into cognitive levels indicated in Table 4. Each level depends on the actual scale of performance, which in turn depends on the test's overall score or mean score.

Table 4. Rating Scale of Cognitive Levels of the Respondents

\begin{tabular}{|c|c|c|}
\hline Points & Scales & Levels \\
\hline $0-5$ & Poor & Lower Cognitive \\
\hline $6-8$ & Fair & Level \\
\hline $9-11$ & Average & \\
\hline $12-15$ & Good & Higher Cognitive \\
\hline $16-20$ & Excellent $\downarrow$ & Level \\
\hline Total & & Sum Column 3 \\
\hline
\end{tabular}

In a single test, in which 20 is the total highest points achieved when all items designed to assess cognitive skills were responded correctly; 0-5 points is considered "poor cognition"; 6-8 points should be seen as "fair cognition"; 9-11 is "average cognition"; 12-15 is regarded as "good cognition"; while 1620 is "excellent cognition." 


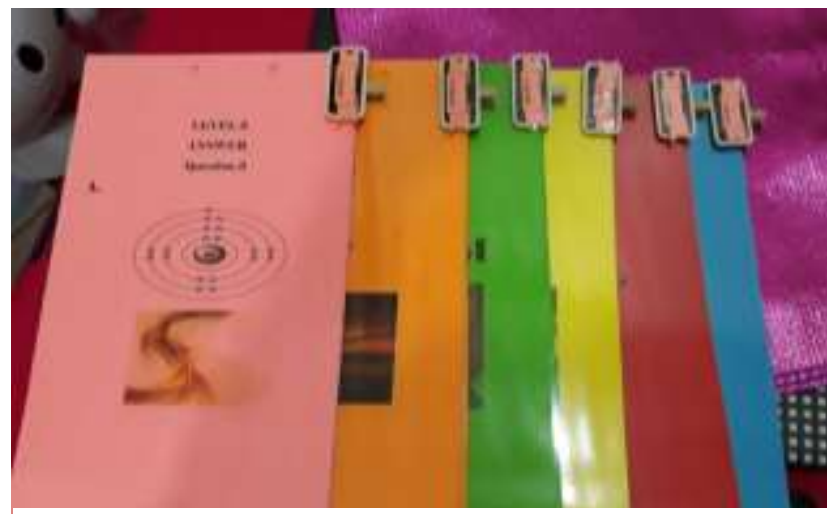

\section{RESULT}

The pre-and-post test of the control group (that is, group A) was first analyzed to determine the reliability of the test using the Pearson correlation coefficient represented by Table 5 .

To be specific, this group had no intervention between and/or before any of the tests.

Figure 3. Answer slides for SBG

Table 5. Pearson's Correlation coefficient of the test instrument of the study

\begin{tabular}{llcc}
\hline & & Pre-test & Post-test \\
\hline Pre-test & Pearson Correlation & 1 & -.134 \\
& Sig. (2-tailed) & & .830 \\
\multirow{3}{*}{ Post-test } & $\mathrm{N}$ & 5 & 5 \\
& Pearson Correlation & -.134 & 1 \\
& Sig. (2-tailed) & .830 & \\
& $\mathrm{~N}$ & 5 & 5 \\
\hline
\end{tabular}

It can be observed from Table 5 that the alpha value is 0.830 , which is very close to 1 . According to Tavakol \& Dennick (2011), a high level for alpha may mean that the items in the test are highly correlated. Thus, it can be concluded that this instrument is intensely reliable.

Table 6. Pre-and-post-test Results of Experimental Group B

\begin{tabular}{ccc}
\hline Respondents & Pre-test & Post-test \\
\hline B1 & 9 & 11 \\
B2 & 8 & 9 \\
B3 & 9 & 11 \\
B4 & 8 & 8 \\
B5 & 8 & 10 \\
\hline Mean & $\mathbf{8 . 6}$ & $\mathbf{9 . 8}$ \\
\hline
\end{tabular}

From the above Table 6, it can be seen that the mean score of 8.6 and 9.8 respondents' pre-test and post-test, respectively, indicated a difference of 1.2 points. These reveal that slight improvement in the total points scored by the respondents of group B. They were able to score more points in the posttest than the pre-test.

Table 7. Pre-and-post-test Results of Experimental Group C

\begin{tabular}{ccc}
\hline Respondents & Pre-test & Post-test \\
\hline C1 & 10 & 13 \\
C2 & 6 & 10 \\
C3 & 7 & 14
\end{tabular}




\begin{tabular}{ccc}
\hline Respondents & Pre-test & Post-test \\
\hline C4 & 9 & 11 \\
C5 & 7 & 12 \\
\hline Mean & $\mathbf{7 . 8}$ & $\mathbf{1 2}$ \\
\hline
\end{tabular}

Table 7, representing the test scores of group C, indicated that the mean scores of post-tests are higher than that of the pre-test with 4.2 points. The mean scores of pre-tests 7.8 and 12 for the posttests indicate a significant increase in the overall scores of the respondents in group C.

Table 8. Pre-and-post-test Results of Experimental group D

\begin{tabular}{ccc}
\hline Respondents & Pre-test & Post-test \\
\hline D1 & 9 & 16 \\
D2 & 5 & 18 \\
D3 & 6 & 18 \\
D4 & 9 & 20 \\
D5 & 8 & 20 \\
\hline Mean & $\mathbf{7 . 4}$ & $\mathbf{1 8 . 4}$ \\
\hline
\end{tabular}

Table 8 above reveals that the mean value of the post-test, 18.4 is higher than that of the pre-test, 7.4, which indicates that the respondents in group D scored higher in the former than the latter. However, this indicated that students demonstrate significant improvement.

\section{DISCUSSION}

The Form IV secondary school chemistry students demonstrated good knowledge of the subject matter in chemical symbols and periodicity based on regular classroom instructions delivered by their teachers. Although most of the respondents could not respond correctly to half of the total test items, they demonstrate a level of cognition we termed "fair cognition" from pre-tests administered to all groups involved in the study. Initially, students performed moderately during pre-test due to limited cognition gained during conventional classroom instruction. With the introduction of intervention which comes with activities to improves one's abilities, the performance becomes dynamic throughout the levels of engagement. The "treatment level 1" indicated a modest improvement in the students' scores. The researchers consider this modest improvement because the items in "level 1 treatment" seek for student's fair cognition. Similarly, Table 4, which represented the rating scale of students' cognitive levels based on individual or mean scores of the test, indicated that 9.8 mean scores fall within the "average scale." It implies that the respondents of Group B were rank under "lower cognitive level."

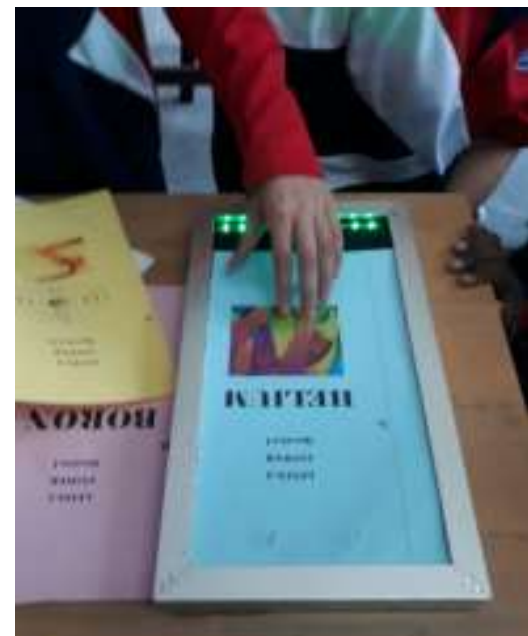

Figure 4. Students playing SBG in the classroom

Subsequently, the mean scores of students in group C improved moderately after receiving the intervention of "treatment level $1 \& 2 "$. It is essential to understand that at this level, complex tasks were introduced. Thus, the respondent's cognition is expected to improve significantly. The mean scores of 12 indicated that the respondents were placed on a "good scale," as observed in Table 4. This category of students reached the initial level of higher cognition. Thus, it is easy for them to score above average on a test. Finally, there is a significant improvement in the cognitive level of respondents in group D. This group received the intervention of "treatment 1,2\&3", a more complex cognitive activities level. The overall mean score of the respondents in this group is 18.4, which falls within the "excellent scale" indicated in Table 4 above. Hence, group D respondents were placed under a higher cognitive level base on their mean score. It implies that the members of this group demonstrated excellent cognition in learning periodicity using the Symp1eriod board game. This study describes that the students' cognitive development increases gradually, from 


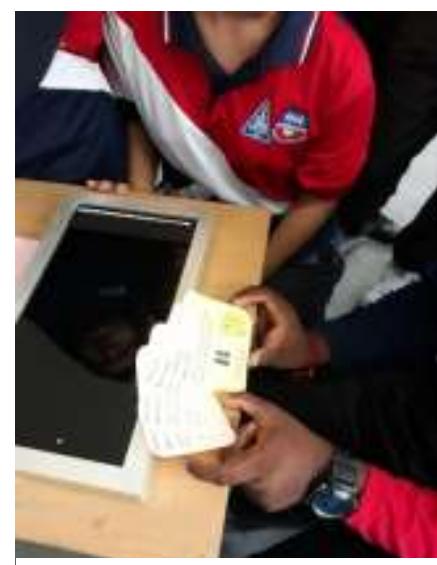

Figure 5. Students preparing to initiate the instructional game

simple to complex, as expressed by (Hanna 2007). According to Munzenmaier \& Rubin (2013), a learner cannot understand a concept if he/she does not first remember it.

Similarly, he/she cannot apply knowledge and concepts if he/she does not understand them. Symperiod Board Game facilitated an essential shift in the instructional focus: from teaching to learning. Its activities were designed to help the learner to recall information. The transition of the educational system from traditional to content-oriented and yet to outcome-oriented demonstrated the effectiveness of educational reforms worldwide (Bernholt \& Parchmann, 2011). The overall results indicated that the instructional game used in the study is significantly effective in enhancing the cognitive development of Form IV students in learning chemical symbols and periodicity in chemistry. However, the respondents were very excited, happy, and mesmerized while playing and at the same time when learning was taking placed. The instructional board game made the learning process very interactive, such that many students wish that they could own it to enable them to play at home.

\section{CONCLUSION}

Some of the objectives of Chemistry subjects in secondary school, as pointed out by Overton et al. (2013) and Talib et al. (2018), are to evaluate the abilities of students to recall and show understanding of chemical facts and patterns principles, terminology, and conventions. Chemistry subject comprises of complex problems that seek complex cognition. Thus, the Symperiod Board Game serves as a digital instrument that enhances student's cognition in learning periodicity. It is imperative to conclude that the poor performance of students in chemistry can be associated with the quality of instruction provided by the teacher during classroom instruction. Other factors that could be associated with poor students' learning of chemistry concepts are the teacher variables (attitude, qualification, attendance at chemistry workshop, condition of service), students variables (choice of career, attitude) and environmentalrelated variables (class size, school location and laboratory adequacy) (Edomwonyi-otu \& Avaa, 2011).

\section{ACKNOWLEDGMENT (optional)}

We wish to express our endless appreciation to the Universiti Teknologi Malaysia for their training, guidance, and support in designing, developing, and integrating the Symperiod Board Game into classroom instruction.

\section{Funding and Conflicts of Interest:}

The authors declare that there is no funding and conflicts of interest for this article.

\section{REFERENCES}

Aliyu, H., Talib, C. A., Aliyu, F., Maimun, A., Malik, A., \& Ali, A. (2020). Predominant Chemical Substances Causing Environmental Degradation as a Result of Climate Change : A Systematic Review. Solid State Technology, 63(1s), 704-720.

Bernholt, S., \& Parchmann, I. (2011). Assessing the complexity of students' knowledge in chemistry. Chemistry Education Research and Practice, 12(2), 167-173. https://doi.org/10.1039/c1rp90021h

Bradley, J. (2014). The Chemist'S Triangle and A General Systemic Approach to Teaching, Learning and Research In Chemistry Education. AJCE, 4(2), 64-79.

Bugaje, B. M. (2013). Qualitative Chemistry Education: The Role of the Teacher. Journal of Applied Chemistry (IOSR-JAC), 4(5), 10-14. https://doi.org/10.1080/00094056.1949.10726229

Chiu, M., \& Wu, H. (2009). The Roles of Multimedia in the Teaching and Learning of the Triplet Relationship in Chemistry. In Multiple representations in chemical education (pp. 251-283). 
Springer. https://doi.org/10.1007/978-1-4020-8872-8

Divjak, B., \& Tomic, D. (2011). The Impact of Game-Based Learning on the Achievement of Learning Goals and Motivation for Learning Mathematics-a Literature Review. Journal of Information Organization Science, 35(1), 15-30.

Edomwonyi-otu, L., \& Avaa, A. (2011). The Challenge of Effective Teaching of Chemistry: A Case Study. Leonardo Electronic Journal of Practices and Technologies, 10(18), 1-8.

Egenfeldt-Nielsen, S. (2006). Overview of research on the educational use of video games. Digital Kompetanse, 1(3), 184-213.

Gee, J. P. (2007). What video games have to teach us about learning and literacy (Revised and updated edition). Palgrave Macmillan.

Gilbert, J. K., \& Treagust, D. F. (2009). Towards a Coherent Model for Macro, Submicro and Symbolic Representations in Chemical Education. 333-350. https://doi.org/10.1007/978-1-4020-8872-8

Hanna, W. (2007). The New Bloom's Taxonomy: Implications for Music Education. Arts Education Policy Review, 108(4), 7-16. https://doi.org/10.3200/AEPR.108.4.7-16

Hays, R. T. (2005). Training Systems Division. Distribution.

Johnstone, A. (1982). Macro- and micro-chemistry. School Science Review, 64, 377-379.

Kraiger, K., Ford, J. K., \& Salas, E. (1993). Application of cognitive, skill-based, and affective theories of learning outcomes to new methods of training evaluation. Journal of Applied Psychology, 78(2), 311-328. https://doi.org/10.1037/0021-9010.78.2.311

Li, M.-C., \& Tsai, C.-C. (2013). Game-Based Learning in Science Education : A Review of Relevant Research. Journal of Science Education and Technology, 22, 877-898. https://doi.org/10.1007/s10956-013-9436-x

Martina Eya, N. (2016). Investigating the Contents of the Senior Secondary School Chemistry Curriculum that can Inculcate Entrepreneurial Skills among Students in Nigeria. International Journal for Cross-Disciplinary Subjects in Education, 6(2), 2195-2201. https://doi.org/10.20533/ijcdse.2042.6364.2015.0303

Mayer, R.E, \& Johnson, C. . (2010). Adding instructional features that promote learning in a game-like environment. Journal of Education and Computer Resources, 42(3), 241-265.

Mayer, Richard E. (2005). Cognitive Theory of Multimedia Learning. The Cambridge Handbook of Multimedia Learning, 31-48. https://doi.org/10.1207/s15326985ep4102_2

Munzenmaier, C., \& Rubin, N. (2013). Bloom's Taxonomy: What's Old Is New Again. Perspectives, 1-47. http://www.elearningguild.com/research/archives/index.cfm?id=164\&action=viewonly\&utm_c ampaign=research-blm13\&utm_medium=email\&utm_source=elg-insider

Overton, T., Potter, N., \& Leng, C. (2013). A study of approaches to solving open-ended problems in chemistry. Chemistry Education Research and Practice, 14(4), 468-475. https://doi.org/10.1039/c3rp00028a

Plass, J. L., O’Keefe, P. A., Biles, M. L., Frye, J., \& Homer, B. D. (2014). Motivational and Cognitive Impact of Badges in Games for Learning. Aera 2014.

Sanchez, J. M. P. (2017). Integrated Macro-Micro-Symbolic Approach in Teaching Secondary Chemistry. Kimika, 28(2), 22-29. https://doi.org/10.26534/kimika.v28i2.22-29

Smith, D. K. (2011). From crazy chemists to engaged learners through education. Nature Chemistry, 3(9), 681-684. https://doi.org/10.1038/nchem.1091

Stieff, M., \& Wilensky, U. (2003). Connected Chemistry-Incorporating Interactive Simulations into the Chemistry Classroom. Journal of Science Education and Technology, 3(12), 285-302.

https://doi.org/10.1023/A 
Talanquer, V. (2011). Macro, Submicro, and Symbolic: The many faces of the chemistry " triplet ." August 2013, 37-41. https://doi.org/10.1080/09500690903386435

Talib, C. A., Aliyu, H., Maimum, A., Malik, A., Siang, K. H., \& Ali, M. (2018). Interactive Courseware as an effective strategy to overcome misconceptions in Acid-base Chemistry. 2018 IEEE 10th International Conference on Engineering Education (ICEED), 240-245.

Tavakol, M., \& Dennick, R. (2011). Making sense of Cronbach's alpha. International Journal of Medical Education, 2, 53-55. https://doi.org/10.5116/ijme.4dfb.8dfd

Ullman, D. (1997). The mechanical design process. McGraw-Hill International.

Vogel, J. ., Vogel, D. ., Cannon-Bowers, J., Bowers, G. ., Muse, K., \& Wright, M. (2006). Computer gaming and interactive simulations for learning: a meta-analysis. Journal of Education Computer Resources, 34(3), 229-243.

Wilson, K. A., Bedwell, W. L., Lazzara, E. H., Salas, E., Burke, C. S., Estock, J. L., Orvis, K. L., \& Conkey, C. (2009). Relationships Between Game Attributes and Learning Outcomes. Simulation \& Gaming, 40(2), 217-266. https://doi.org/10.1177/1046878108321866 